\title{
THE CONTRAST IN TRACE ELEMENT CHEMISTRY AND VOLATILE COMPOSITION BETWEEN FLUID INCLUSIONS IN FIBROUS AND OCTAHEDRAL DIAMONDS
}

\author{
EM Smith1, MG Kopylova 1, GM Nowell 2, DG Pearson 3, J Ryder4, VP Afanasiev 5 \\ 1. University of British Columbia, Vancouver, Canada, 2. Durham University, Durham, UK \\ 3. University of Alberta, Edmonton, Canada, 4. Dianor Resources Inc., Val-d'Or, Canada \\ 5. Sobolev Institute of Geology and Mineralogy, Novosibirsk, Russia
}

\section{INTRODUCTION}

Studies of fluid inclusions in diamonds have been limited by several factors. One factor is that studies have focused on fibrous diamonds, because they contain abundant fluid inclusions. Octahedral diamonds almost never host fluid inclusions, at least that are documented easily. Here the term "octahedral" is used here to refer to genesis by non-fibrous, facetted $\{111\}$ growth, not necessarily the eventual morphology.

A second limitation is that the fibrous diamonds studied are relatively young compared to the majority of octahedral diamonds. These two factors mean that our knowledge of fluid equilibrated with diamond is limited to young, fibrous diamond-forming fluids. This study focuses on two unique diamond suites to address these issues: Archean fibrous diamonds and fluid inclusion-bearing octahedral diamonds.

\section{SAMPLES}

Two diamond suites were studied. The first consists of 6 translucent, grey fibrous diamonds recovered from an Archean metaconglomerate in the Michipicoten Greenstone Belt of the Wawa subprovince, Canada. Three diamonds are fibrous coatings over octahedral cores, while the other three are fibrous cuboids. The diamonds were originally emplaced by a kimberlite into a $>2.7$ Ga nucleus of the Superior craton (Kopylova et al., 2011). The Wawa fibrous diamonds are unique because they are close in age to, or slightly older than, their $\sim 2.7 \mathrm{Ga}$ host. Thus, the contained fluid inclusions may be the oldest mantle fluids available for study.

Fluid inclusion compositions are salinecarbonatitic, based on electron microprobe analysis. The sub-micron-size fluid inclusions contain crystallized solid daughter phases and residual fluid. Daughter minerals in the Wawa diamonds include sylvite, halite, dolomite, and $\mathrm{Ca}-\mathrm{Mg}$-Fe- $\mathrm{Ba}$ carbonates, revealed by $\mathrm{X}$-ray diffraction (Smith et al., 2011). The fluid inclusions coexist with P-type mineral microinclusions like olivine and Cr-pyrope, indicating a harzburgitic diamond origin.

The second suite consists of 5 non-fibrous, octahedral, alluvial diamonds from the Northeastern Siberian Platform. The diamonds are rounded, equant to elongate octahedra with an overall yellow-orange or grey colour, and mechanical abrasion suggestive of a Precambrian primary source (Afanas'ev et al., 2009). Their fluid inclusions are $1-40 \mu \mathrm{m}$ across, colourless, monophasic, and nearly flat, with polygonal boundaries. They lie along healed fractures in the diamond. The fluid inclusions are secondary, but originate from the diamond stability field, as the hosting fractures within the diamonds are 


\section{$10^{\text {th }}$ International Kimberlite Conference, Bangalore - 2012}

healed. Rutile, coesite, and kyanite are found as inclusions with imposed diamond morphology as well as along fractures, consistent with an eclogititc paragenesis.

\section{METHODS}

The Wawa fibrous diamonds were analyzed by infrared spectroscopy to gauge bulk fluid inclusion volatiles not represented in electron microprobe analysis. Infrared spectroscopy was carried out at the University of Alberta, Canada.

Raman spectroscopy was used to measure compositions of fluid inclusions in the Siberian, octahedral diamonds. Spectra were measured at Durham University, UK, using a $532 \mathrm{~nm}$ green laser and $1800 \mathrm{~g} / \mathrm{mm}$ grating. The Siberian diamond fluid inclusions were also examined by microthermometry in the range of $-180-20^{\circ} \mathrm{C}$ using a heating/cooling stage at the University of British Columbia, Canada.

Trace element and $\mathrm{Sr}$ isotope measurements followed the methodology described by McNeill et al. (2009) and Klein-BenDavid et al. (2010), employing off-line laser ablation to accumulate a sample in a closed system. Samples were collected and analyzed at Durham University, UK.

\section{RESULTS AND DISCUSSION}

\section{Volatile Components}

Infrared spectroscopy of the Wawa, fibrous diamonds shows water as the primary volatile. An average concentration (bulk diamond) of $\sim 100$ ppm was calculated from peak height at $3400 \mathrm{~cm}-$ 1 (Weiss et al., 2010). All spectra show carbonate peaks, from carbonate daughter minerals that have crystallized from the fluid. Small $\mathrm{CO} 2$ peaks were also found in two diamonds. Nitrogen is poorly aggregated in all the fibrous diamonds, indicating that the diamonds were essentially contemporaneous with volcanic sampling/ transport.
Raman spectra of the fluid inclusions in Siberian, octahedral diamonds reveal $\mathrm{CO} 2$ and $\mathrm{N} 2$. Estimated molar proportions of $\mathrm{N} 2 /(\mathrm{CO} 2+\mathrm{N} 2)$ are within $0.2-0.8$, based on peak areas (Burke, 2001). This composition agrees with results from Tomilenko et al. (1997) for diamonds from the same NE Siberian placer. Diamond peaks are shifted upward by $0.6 \mathrm{~cm}-1$ near the inclusions, corresponding to a $\sim 0.3 \mathrm{GPa}$ local pressure increase (Grimsditch et al., 1978), which can be taken as a minimum pressure in the fluid inclusions. More importantly, fracture healing and polygonal inclusion boundaries point to fluid trapping within the diamond stability field. Elastic deformation of the inclusion walls likely relieves some fluid inclusion pressure due to their flat and irregular shapes (Burnley and Davis, 2004).

Upon warming in the range $-180-20^{\circ} \mathrm{C}$ the fluid inclusions show either no changes, or exhibit melting of a single solid $\mathrm{CO} 2$ phase (Figure 1). This behaviour is consistent with higher fluid densities than those of crustal fluid inclusions (Van

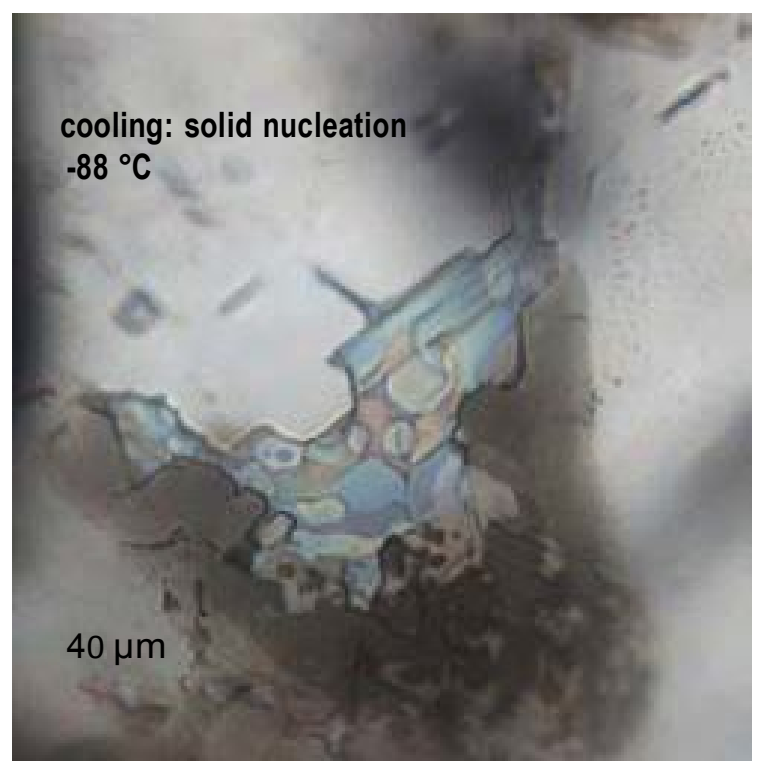

Figure 1. Example of spontaneous nucleation of solid $\mathrm{CO} 2$ upon cooling. The solids appear as multiple rounded blobs that are brighter than the surrounding fluid. The solids quickly reorganized into two discrete blobs comprising $\sim 40 \%$ of the inclusion volume. Upon subsequent heating, final melting occurred at $-63{ }^{\circ} \mathrm{C}$. 


\section{0 $^{\text {th }}$ International Kimberlite Conference, Bangalore - 2012}

den Kerkhof and Thiéry, 2001). Solids occupy $30-90 \%$ of the inclusion volume at the maximum extent of solidification.

A strong contrast is evident between the fluid inclusions in Wawa fibrous diamonds and the Siberian octahedral diamonds. The Wawa fluid is a volatile-rich saline- carbonatitic melt, with water being the dominant volatile. Fibrous diamond fluid inclusions typically contain $10-$ $25 \%$ water (Weiss et al., 2010) and only minor amounts of $\mathrm{CO} 2$, as most of the carbon is present as carbonate (Navon et al., 1988).

However, the Siberian octahedral diamonds contain fluid inclusions that are totally volatile, $\mathrm{CO} 2$ and N2 mixtures. Small amounts of graphite and other minute solids may accompany the fluids in healed fractures, but these fluid inclusions contain nothing like the daughter minerals that dominate fibrous diamond fluid inclusions.

\section{TRACE ELEMENTS}

Chondrite normalised trace element patterns for all samples are shown in Figure 2. The octahedral, Siberian diamond fluids exhibit similar patterns across all 5 diamonds, with elevated Un, $\mathrm{Zrn}$, and Hfn. The octahedral diamond fluids are distinct from the fibrous, Wawa diamond fluids. The Wawa samples can be divided into two groups, most easily distinguished by contrasting $\mathrm{Thn} / \mathrm{Un}$ ratios. Interestingly, the high $\mathrm{Thn} / \mathrm{Un}$ group corresponds to fibrous diamond coats (W1, W1(A2), W7, W9) and the low Thn/Un group corresponds to fibrous cuboids (W14, W29, W50).

The octahedral diamond fluids have generally flat REE patterns $(\mathrm{Lan} / \mathrm{Ybn}=0.5-7)$, with either mild LREE enrichment or mild HREE enrichment and weak negative $\mathrm{Eu}$ anomalies. The elevated HREE and low Lan/Ybn of the Siberian fluids suggests that garnet breaks down to contribute to the fluid.

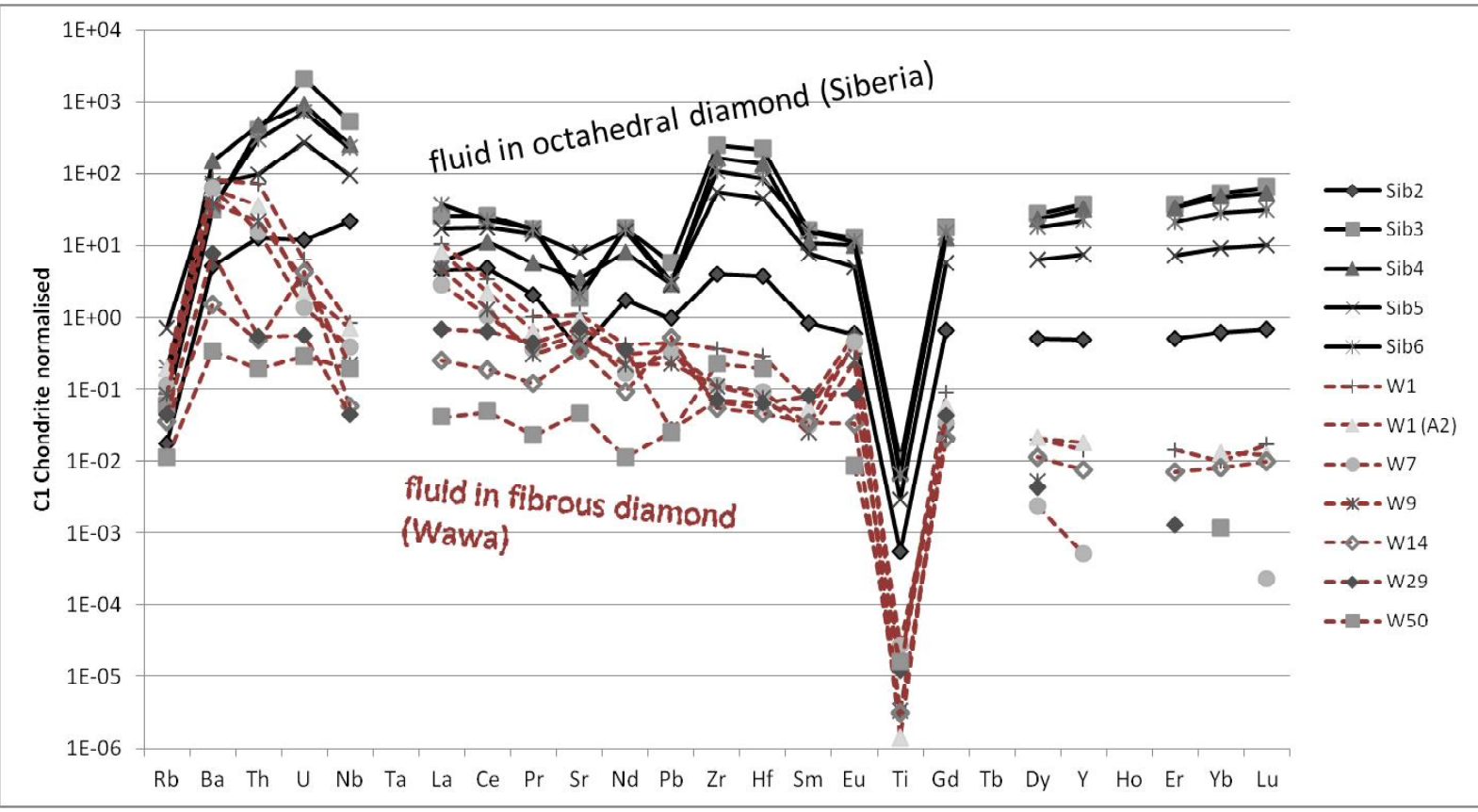

Figure 2. Trace element data, normalised to C1 chondrite (McDonough and Sun, 1995) and the diamond mass difference before and after ablation. 


\section{$1^{\text {th }}$ International Kimberlite Conference, Bangalore - 2012}

In contrast, the Wawa fibrous diamond fluids have steeply-sloping patterns $(\mathrm{Lan} / \mathrm{Ybn}=30$ 1000). The high Lan/Ybn indicates residual garnet control, as in small degree alkalic melts from lherzolites. Fibrous coat samples (W1, W1(A2), W7, W9) have pronounced positive Eu anomalies $\left(\mathrm{Eu} / \mathrm{Eu}^{*}=1.8-3.5\right)$ compared to fibrous cuboid samples, as well as stronger LREE enrichment. Positive $\mathrm{Eu}$ anomalies may suggest original derivation of the fluid from shallow, plagioclasebearing depths.

A comparison with other diamond fluid inclusion trace element patterns from the literature is given in Figure 3. The fibrous, Wawa diamonds correspond somewhat to the "table" category of pattern shapes defined by Weiss et al. (2009), based on high Ban, Thn, Un, and Lan compared to Nbn. Such patterns are characterized by high degrees of inter-element fractionation, particularly between HFSE and LILE. However, the Wawa fluids differ from the "table" category by having notably higher Srn/Ndn, Zrn/Smn, and Hfn/Smn.

A closer match to Wawa fibrous diamond fluids is offered by fibrous diamond fluids from the Pandakimberlite, Ekati mine, NWT (Figure 4) (Tomlinson et al., 2009), whose saline-carbonatitic fluid compositions also resemble those from Wawa (Tomlinson et al., 2006). Both the Wawa and Panda fluids have Srn/ $\mathrm{Ndn}>1$, a feature that has only been observed in saline-type diamond fluid inclusions (McNeill, 2011).

The octahedral, Siberian diamond fluids do not bear strong resemblance to any group of diamond fluids analysed so far, in that they have relatively little primitive mantle normalised interelement fractionations. The increasing sequence Rbn, Ban, Thn, to Un resembles the "fibrous low" patterns of Rege et al. (2010), but the octahedral, Siberian diamond fluids have anomalously high $\mathrm{Zrn} / \mathrm{Smn}$ and $\mathrm{Hfn} / \mathrm{Smn}$, and do not exhibit the down-bowed LREE shape, negative Y anomaly, or low $\mathrm{Zrn} / \mathrm{Hfn}$ ratio that characterize the "fibrous low" group (Figure 3). It is possible that this unusual trace element signature arises partly from minute solid inclusions that accompany fluids along the healed fractures, or from nanoinclusions in the surrounding diamond.

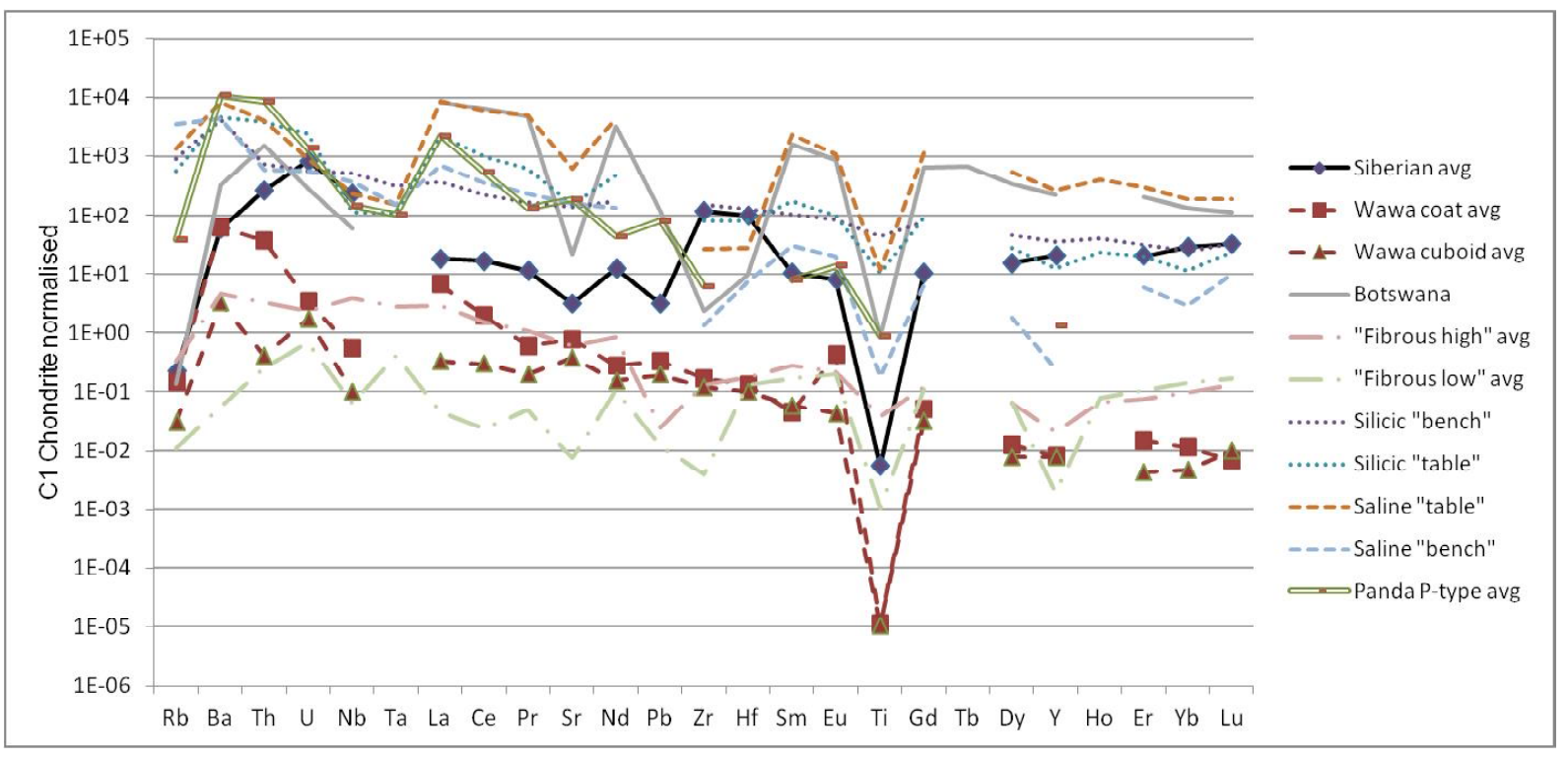

Figure 3. Trace element patterns of average octahedral, Siberian diamond fluid, average Wawa fibrous coat, and average Wawa fibrous cuboid compared to patterns from the literature. All values normalised to C1 chondrite (McDonough and Sun, 1995). Data sources: Botswana (KleinBenDavid et al., 2010); fibrous high, fibrous low, bench and table patterns (Rege et al., 2010); Panda P-type (Tomlinson et al., 2009). 


\section{$1^{\text {th }}$ International Kimberlite Conference, Bangalore - 2012}

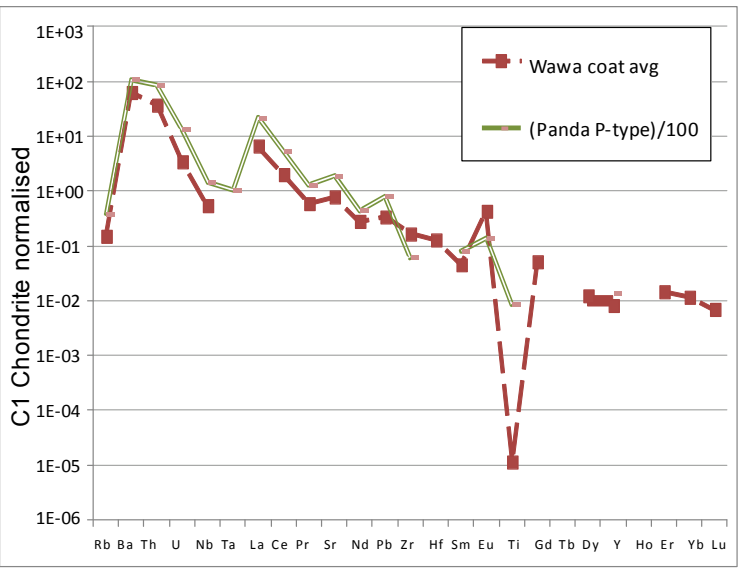

Figure 4. Comparison between the trace element pattern shapes of Wawa, fibrous diamond coats and an average of six P-type fibrous diamonds from the Panda kimberlite (Ekati) (Tomlinson et al., 2009). The Panda pattern is vertically shifted to aid in comparison.

\section{Sr Isotopes}

Wawa fibrous diamonds gave $87 \mathrm{Sr} /$ $86 \mathrm{Sr}$ values of $0.7042-0.7078$. Calculating initial $87 \mathrm{Sr} / 86 \mathrm{Sr}$ using $\mathrm{Rb} / \mathrm{Sr}$ ratios and an age of $2.7 \mathrm{Ga}$ yields values of $0.699-0.702$. Four samples have extremely low initial $87 \mathrm{Sr} / 86 \mathrm{Sr}$, approaching the Solar System initial of 0.69889, but also reflecting relatively large uncertainties in the measured $\mathrm{Rb} / \mathrm{Sr}$ ratios due to low $\mathrm{Rb}$ contents.

$\mathrm{Sr}$ isotopes in the Wawa fibrous diamonds have a general positive correlation between $\mathrm{Rb} /$ $\mathrm{Sr}$ and $87 \mathrm{Sr} / 86 \mathrm{Sr}$ ratios but they do not form a geologically reasonable isochron (i.e. greater than or equal to the $2.7 \mathrm{Ga}$ deposition age of the Wawa metaconglomerate diamond host). This indicates that the fluids were isotopically heterogeneous, similar to findings from Botswana fibrous diamonds (Klein- BenDavid et al., 2010). While the uncertainties on the $\mathrm{Rb} / \mathrm{Sr}$ ratios and resulting initial ratios are high, the low calculated ${ }^{87} \mathrm{Sr}^{86}{ }^{86} r_{i}$ ratios call for a source that experienced timeintegrated depletion of $\mathrm{Rb} / \mathrm{Sr}$. This contrasts with the Botswanan fibrous diamond fluid sources (Klein-BenDavid et al., 2010), but is consistent with some Slave craton fibrous diamonds (Mc Neill, 2011).
Only one of the octahedral diamond samples contained sufficient $\mathrm{Sr}$ to allow ${ }^{87} \mathrm{Sr} /{ }^{86} \mathrm{Sr}$ measurement. Its very radiogenic ${ }^{87} \mathrm{Sr} /{ }^{86} \mathrm{Sr}$ value of $0.7130 \pm 2$ is coupled with a $\mathrm{Rb} / \mathrm{Sr}$ ratio that is too low to produce this radiogenic signature over any reasonable timescale. For example, an assumed age of $3 \mathrm{Ga}$ gives a ${ }^{87} \mathrm{Sr} /{ }^{86} \mathrm{Sr}_{\mathrm{i}}$ value of 0.709 , well above bulk earth. Therefore, this Siberian, octahedral diamond has inherited a significant radiogenic $\mathrm{Sr}$ signature. This would require input from a high $\mathrm{Rb} / \mathrm{Sr}$ phase that was isolated from the convecting mantle. Such an evolution has been observed for some gem diamond fluid sources from the Slave craton (McNeill, 2011).

\section{Fluid Origins}

The remarkable similarity of major and trace element composition between Wawa fibrous diamond fluid inclusions and saline-carbonatitic fibrous diamond fluids from the Ekati and Diavik mines in the Slave craton, Canada, suggests common fluid generating and growth mechanisms despite being in separate cratons and being separated by more than $2.5 \mathrm{Ga}$. Similar salinecarbonatitic fluid compositions are also present in some fibrous diamonds from the Kaapvaal and Siberian cratons (Izraeli et al., 2001; Zedgenizov et al., 2007). The Wawa fluid inclusions record direct evidence of Archean diamond growth from fluids of carbonatitic-character that are analogous to Phanerozoic examples. For the case of Wawa, Archean fibrous diamond genesis may also entail broader metasomatic processes, based on proposed genetic links between fibrous diamonds and kimberlites (e.g. Akagi and Masuda, 1988; Navon et al., 1988; Tomlinson et al., 2009; Weiss et al., 2011). A link to kimberlites is supported by $\mathrm{Sr}$ isotopes in the Wawa fluids, which are consistent with an asthenospheric origin.

In contrast, there are few examples of $\mathrm{CO}_{2}-$ $\mathrm{N} 2$ fluid inclusions from the mantle to draw in parallel with the Siberian, octahedral diamonds. 


\section{$10^{\text {th }}$ International Kimberlite Conference, Bangalore - 2012}

The closest match is olivine- hosted $\mathrm{CO}_{2}-\mathrm{N}_{2}$ fluid inclusions in spinel dunites from the Canary Islands (Andersen et. al., 1995). While the convecting mantle is one potential contributor for $\mathrm{CO}_{2}-\mathrm{N}_{2}$, the radiogenic $\mathrm{Sr}$ in the Siberian diamonds requires input from the sub-continental lithospheric mantle.

The anomalous levels of $\mathrm{N}$ in the Siberian fluids suggest either an efficient mechanism of $\mathrm{N}$ enrichment, or derivation from a N-rich source, such as subducted crust with organic N. A possible $\mathrm{N}$-enrichment mechanism could be partial melting or recrystallization of $\mathrm{NH} 4+$ bearing clinopyroxene (Watenphul et al., 2010) or other $\mathrm{NH}^{+}$ bearing silicates. If $\mathrm{NH}_{4}{ }^{+}$breaks down into $\mathrm{N}_{2}$ and water, the water could be absorbed by surrounding minerals or partial melt, whereas $\mathrm{N}_{2}$ may exsolve as a relatively insoluble supercritical fluid. Such a scenario may produce bubbles of $\mathrm{N}_{2}$.

If $\mathrm{CO}_{2}$ is present, it could scavenge $\mathrm{N}_{2}$ to make a mixed fluid like the one trapped in the Siberian octahedral diamonds. One sign that mantle $\mathrm{CO}_{2}$ could have an affinity to scavenge $\mathrm{N}_{2}$ may be taken from the $13 \mathrm{C} / 12 \mathrm{C}$ fractionation model proposed by Cartigny et al. (2001) for eclogitic diamonds. In this model, $\mathrm{CO}_{2}$ escapes from a diamond-13 forming system, leaving it progressively depleted in C. Interestingly, the N content of eclogitic diamonds decreases systematically toward lower $\delta 13 \mathrm{C}$ values, which could indicate that $\mathrm{N}_{2}$ is scavenged by the escaping $\mathrm{CO}_{2}$.

Aside from $\mathrm{CO}_{2}$ and $\mathrm{N}_{2}$, the Siberian fluid must have contained radiogenic initial Sr, likely inherited from a source with a high $\mathrm{Rb} / \mathrm{Sr}$ phase. The high $\mathrm{Rb} / \mathrm{Sr}$ requirement, coupled with high $\mathrm{Zrn} / \mathrm{Smn}, \mathrm{Un} / \mathrm{Thn}$, and $\mathrm{Nbn} / \mathrm{Lan}$ could point towards the involvement of K-rich amphibole (Konzett et al., 1997; Moine et al., 2001). This would help explain the elevated $\mathrm{Zr}_{\mathrm{n}}$ and $\mathrm{Hf}_{\mathrm{n}}$.

\section{CONCLUSIONS}

Fluid inclusions in the two studied diamond suites differ in both composition and trace element characteristics. The Archean fibrous diamonds from Wawa contain saline- carbonatitic fluids, whose trace element characteristics are similar to comparable Phanerozoic saline - carbonatitic fibrous diamonds. Initial $87 \mathrm{Sr} / 86 \mathrm{Sr}$ ratios indicate that Wawa fluids are consistent with an asthenospheric source, while the Siberian fluids require contribution from a lithospheric source. The secondary fluid inclusions trapped in octahedral, Siberian diamonds are $\mathrm{CO}_{2}-\mathrm{N}_{2}$ mixtures, unlike the fluids found in fibrous diamond. Their unusual trace element systematics may reflect traces of solids trapped along fractures with fluid inclusions.

There seems to be a commonality between the fluids forming Wawa fibrous diamonds at 2.7 $\mathrm{Ga}$ and some much younger fibrous diamonds, implying similar diamond- forming processes.

\section{References}

Afanas'ev, V., Zinchuk, N. and Logvinova, A., 2009. Distribution of placer diamonds related to Precambrian sources. Geology of Ore Deposits, 51(8): 675-683.

Akagi, T. and Masuda, A., 1988. Isotopic and elemental evidence for a relationship between kimberlite and Zaire cubic diamonds. Nature, 336(6200): 665667.

Andersen, T., Burke, E.A.J. and Neumann, E.R., 1995. Nitrogen-rich fluid in the upper mantle: fluid inclusions in spinel dunite from Lanzarote, Canary Islands. Contributions to Mineralogy and Petrology, 120(1): 20-28.

Burke, E.A.J., 2001. Raman microspectrometry of fluid inclusions. Lithos, 55(1-4): 139-158.

Burnley, P.C. and Davis, M.K., 2004. Volume changes in fluid inclusions produced by heating and pressurization: An assessment by finite element modeling. The Canadian Mineralogist, 42(5): 13691382.

Grimsditch, M.H., Anastassakis, E. and Cardona, M., 1978. Effect of uniaxial stress on the zone-center optical phonon of diamond. Physical Review B, 18(2): 901-904. 


\section{$1^{\text {th }}$ International Kimberlite Conference, Bangalore - 2012}

Izraeli, E.S., Harris, J.W. and Navon, O., 2001. Brine inclusions in diamonds: a new upper mantle fluid. Earth and Planetary Science Letters, 187(3-4): 323332.

Klein-BenDavid, O. et al., 2010. Mixed fluid sources involved in diamond growth constrained by $\mathrm{Sr}-$ $\mathrm{Nd}-\mathrm{Pb}-\mathrm{C}-\mathrm{N}$ isotopes and trace elements. Earth and Planetary Science Letters, 289: 123-133.

Konzett, J., Sweeney, R.J., Thompson, A.B. and Ulmer, P., 1997.

Potassium amphibole stability in the upper mantle: An experimental study in a peralkaline KNCMASH system to 8.5 GPa. Journal of Petrology, 38(5): 537568.

Kopylova, M.G., Afanasiev, V.P., Bruce, L. and Ryder, J., 2011.

Diamondiferous conglomerate preserves evidence for kimberlite and the deep cratonic root of the Mesoarchean Southern Superior craton.

Mineralogical Magazine, 75. Goldschmidt Conference Abstracts: 1221.

McDonough, W.F. and Sun, S.S., 1995. The composition of the Earth. Chemical Geology, 120(3-4): 223-253.

McNeill, J.C.R., 2011. New techniques for trace element and radiogenic isotope measurement of diamonds: Their application to diamond petrogenesis and source tracing, $\mathrm{PhD}$ Thesis, Durham University, Durham, U.K., 281 pp.

McNeill, J.C.R. et al., 2009. Quantitative analysis of trace element concentrations in some gem-quality diamonds. Journal of Physics: Condensed Matter, 21(36): 364207-364220.

Moine, B.N., Grégoire, M., O’reilly, S.Y., Sheppard, S.M.F. and Cottin,

J.Y., 2001. High field strength element fractionation in the upper mantle: Evidence from amphibolerich composite mantle xenoliths from the Kerguelen Islands (Indian Ocean). Journal of Petrology, 42(11): 2145-2167.

Navon, O., Hutcheon, I.D., Rossman, G.R. and Wasserburg, G.J., 1988.

Mantle-derived fluids in diamond microinclusions. Nature, 335(6193): 784-789.
Rege, S. et al., 2010. Trace-element patterns of fibrous and monocrystalline diamonds: Insights into mantle fluids. Lithos, 118(3-4): 313-337.

Smith, E.M. et al., 2011. Transmission X-ray diffraction as a new tool for diamond fluid inclusion studies. Mineralogical Magazine, 75(5): 2657-2675.

Tomilenko, A.A., Chepurov, A.L., Pa1/4lyanov, Y.N., Pokhilenko, L.N. and Shebanin, A.P., 1997. Volatile components in the upper mantle. Russian Geology and Geophysics, 38(1): 294-303.

Tomlinson, E.L., Jones, A.P. and Harris, J.W., 2006. Co-existing fluid and silicate inclusions in mantle diamond. Earth and Planetary Science Letters, 250: 581-595.

Tomlinson, E.L., Muller, W. and E.I.M.F., 2009. A snapshot of mantle metasomatism: Trace element analysis of coexisting fluid (LA-ICP- MS) and silicate (SIMS) inclusions in fibrous diamonds. Earth and Planetary Science Letters, 279: 362-372.

Van den Kerkhof, A. and Thiéry, R., 2001. Carbonic inclusions. Lithos, 55(1-4): 49-68.

Watenphul, A., Wunder, B., Wirth, R. and Heinrich, W., 2010.

Ammonium-bearing clinopyroxene: A potential nitrogen reservoir in the Earth's mantle. Chemical Geology, 270(1-4): 240-248.

Weiss, Y., Griffin, W.L., Bell, D.R. and Navon, O., 2011. High-Mg carbonatitic melts in diamonds, kimberlites and the sub-continental lithosphere. Earth and Planetary Science Letters, 309(3-4): $337-$ 347.

Weiss, Y., Griffin, W.L. and Navon, O., 2009. Trace elements of fibrous diamonds. EGU 2009, Abstract 802, Geophysical Research Abstracts, 11.

Weiss, Y., Kiflawi, I. and Navon, O., 2010. IR spectroscopy: Quantitative determination of the mineralogy and bulk composition of fluid microinclusions in diamonds. Chemical Geology, 275(1-2): 26-34.

Zedgenizov, D., Ragozin, A. and Shatsky, V., 2007. Chloride-carbonate fluid in diamonds from the eclogite xenolith. Doklady Earth Sciences, 415(2): 961-964. 